\title{
Contribuições da formação colaborativa para o ensino da leitura junto ao aluno com transtornos funcionais específicos
}

\author{
Cristiane Malinoski Pianaro Angelo \\ Universidade Estadual do Centro-Oeste \\ cristiane.mpa@gmail.com
}

Maria Andreia Batista Blum Secretaria do Estado da Educação do Paraná mariaandreiabatista@gmail.com

Elsa Midori Shimazaki Universidade Estadual de Maringá emshimazaki@uem.br

\section{Resumo}

Este artigo tem por objetivo apresentar e discutir os resultados de uma formação continuada colaborativa voltada ao ensino da leitura ao aluno com Transtornos Funcionais Específicos (TFE). A pesquisa fundamentou-se nos pressupostos da teoria histórico-cultural no que concerne à aprendizagem e nas orientações metodológicas da pesquisa colaborativa, envolvendo uma das pesquisadoras e uma professora de $4^{\circ}$ ano do Ensino Fundamental de uma escola pública, classe na qual se encontrava matriculado um aluno com TFE. Os resultados demonstraram que o trabalho colaborativo junto ao professor contribuiu para o atendimento ao aluno com TFE. Com ações pedagógicas planejadas e sistematizadas, o professor atuou na zona de desenvolvimento proximal dos alunos e consolidou-a. Dessa forma, a pesquisa mostra a necessidade de desafiar o aluno para além de seu nível de desenvolvimento real com a proposição de situações desencadeadoras do nível de desenvolvimento potencial.

Palavras-chave: Leitura; Pesquisa colaborativa; Formação continuada; Transtornos Funcionais Específicos.

\section{Abstract}

This article aims to present and discuss the results of continuing collaborative education focused on teaching reading to students with Specific Functional 
Disorders (SFD). The research was based on the assumptions of the historicalcultural theory and the methodological orientations of the collaborative research, involving one of the researchers and a 4th-grade primary school teacher from a public school, in which a student with SFD was enrolled. The results showed that the collaborative work with the teacher contributed to the assistance to the student with SFD. The teacher worked through the students' proximal development zone and consolidated it with planned and systematized pedagogical actions. Thus, the research shows the need to challenge the student beyond his real development level with the proposition of situations that trigger the potential development level.

Keywords: Reading; Collaborative research; Continuing formation; Specific Functional Disorders.

\section{Introdução}

Transtornos Funcionais Específicos (TFE) é um termo amplo que diz respeito a um conjunto de dificuldades relacionadas à aquisição e ao uso de habilidades acadêmicas na leitura, na escrita e na matemática. No Manual Diagnóstico e Estatístico de Transtornos Mentais (DSM-V), organizado pela Associação Psiquiátrica Americana (APA, 2014), os TFE constituem os Transtornos Específicos da Aprendizagem, os quais são definidos como dificuldades na aprendizagem e no uso de habilidades acadêmicas, de modo a causar interferência significativa no desempenho acadêmico ou profissional ou nas atividades cotidianas. Em se tratando de leitura e escrita, apontam-se as seguintes características:

1.Leitura de palavras de forma imprecisa ou lenta e com esforço (p. ex., lê palavras isoladas em voz alta, de forma incorreta ou lenta $e$ hesitante, frequentemente adivinha palavras, tem dificuldade de soletrá-las).2. Dificuldade para compreender o sentido do que é lido (p. ex., pode ler o texto com precisão, mas não compreende a sequência, as relações, as inferências ou os sentidos mais profundos do que é lido).3. Dificuldades para ortografar (ou escrever ortograficamente) (p. ex., pode adicionar, omitir ou substituir vogais e consoantes).4. Dificuldades com a expressão escrita (p. ex., comete múltiplos erros de gramática ou pontuação nas frases; emprega organização inadequada de parágrafos; expressão escrita das ideias sem clareza) [...] (APA, 2014, p. 67). 
O aluno que apresenta TFE não é público-alvo da educação especial: "[...] trata-se apenas de uma criança/adolescente que aprende de uma forma diferente, pois apresenta capacidade motora adequada, inteligência na média ou acima, audição e visão normais, assim como ajustamento emocional" (PARANÁ, 2013, p.44). Desse modo, a legislação federal não prevê Atendimento Educacional Especializado (AEE) em Sala de Recursos Multifuncionais (SRM) ou qualquer outro programa de educação especial, cabendo, então, ao professor da classe comum propiciar as condições para que o aluno com TFE aproprie-se da leitura, da escrita e dos cálculos, de maneira a avançar no processo de escolarização e a obter desempenhos mais satisfatórios nas práticas de linguagem e de matemática no contexto social. A legislação do Estado do Paraná diferencia-se da legislação federal ao estender o atendimento em SRM também aos alunos com TFE:

A Sala de Recursos Multifuncionais atenderá estudantes matriculados em instituições de ensino vinculadas ao Sistema Estadual de Ensino, com diagnóstico de deficiência intelectual, deficiência física neuromotora, transtornos globais do desenvolvimento, transtornos funcionais específicos, com problemas de aprendizagem, que requeiram análise $e$ planejamento de ações de intervenção sobre os resultados avaliativos_dos estudantes (PARANÁ, 2018, p. 02, grifos nossos).

O professor necessita de formação específica para avaliar quais habilidades de leitura, de escrita e de cálculos o aluno com TFE domina e quais habilidades ele ainda necessita desenvolver e, a partir desse levantamento, elaborar planejamentos com atividades que possam suprir ou minimizar as dificuldades. No que se refere à leitura e à escrita, Menegassi (2010a; 2010b) afirma que conduzir o aluno pelas etapas que compõem os processos de leitura e de escrita leva-o a apropriar-se de modo gradativo da efetivação do processo, a perceber a transformação dos próprios conhecimentos. Segundo esse autor, as etapas desses processos ocorrem de forma concomitante e recursiva, dependendo uma da outra para sua realização, propiciando um conjunto harmônico de estratégias e habilidades no leitor e produtor de textos. No que se refere às situações de alunos com TFE, compreende-se que o trabalho com os processos de leitura e de escrita mostra-se pertinente ao proporcionar condições para que eles superem suas 
dificuldades progressivamente, dando-lhe confiança e segurança ao entender que é capaz de produzir suas próprias palavras na leitura e na produção textual (BAKHTIN/VOLOCHINOV, 2006[1929]).

Com base nessas considerações, este artigo tem por objetivo apresentar e discutir os resultados de uma formação continuada colaborativa voltada ao ensino do processo da leitura ao aluno com diagnóstico de TFE, amplamente discutida na tese de doutorado de Angelo (2015). Para tanto, a pesquisa envolveu, além de uma pesquisadora, uma professora que, na ocasião, atuava em um $4^{\circ}$ ano do Ensino Fundamental de uma escola pública, classe na qual se encontrava matriculado um aluno com TFE. Partiu-se do pressuposto de que a mediação colaborativa entre pesquisador e professor pode contribuir para o processo de ensino e de aprendizagem, orientando as ações docentes, auxiliando o professor a repensar suas práticas no que se refere ao ensino da leitura (ANGELO, 2015).

\section{Aspectos teóricos da pesquisa}

Segundo a perspectiva histórico-cultural, o homem constitui-se a partir das interações dialéticas com o outro, com o mundo: todas as funções psicológicas têm origem no social (VYGOTSKY, 1998; VYGOTSKY; LURIA, 1996). Dessa forma, a constituição do sujeito, com seus conhecimentos e formas de ação na realidade - intrapsicológico no indivíduo, tem como alicerce a relação eu-outro, os espaços da intersubjetividade - interpsicológicos. De acordo com essa teoria, o processo de conversão de algo interpsicológico para algo intrapsicológico não se dá por mera repetição, mas pela reconstituição de todo o processo envolvido. Esse processo pressupõe a mediação, especialmente a mediação da linguagem através dos signos, a qual não se configura como mera interposição, mas como um processo que sustenta a relação e forma a consciência do sujeito.

Vygotsky (1998, p. 74) chama "de internalização a reconstrução interna de uma operação externa”, ilustrando o processo de internalização como uma série de transformações: “i) Uma operação que inicialmente representa uma atividade externa é reconstruída e começa a ocorrer internamente"; "ii) Um processo interpessoal é transformado num processo intrapessoal. Todas as funções no desenvolvimento [...] aparecem duas 
vezes: primeiro, entre pessoas (interpsicológica), e, depois, no interior [...] (intrapsicológica)"; iii)"A transformação de um processo interpessoal num processo intrapessoal é o resultado de uma longa série de eventos ocorridos ao longo do desenvolvimento"(VYGOTSKY, 1998, p. 75).

As transformações internas a partir das inter-relações são fatores essencialmente humanos que são constituídos em diferentes tempos de acordo com cada indivíduo. A internalização tem como base fundamental as experiências vivenciadas que reconstroem as atividades psicológicas, pois "o desenvolvimento psicológico está solidamente introduzido no contexto de todo desenvolvimento social [...]" (VYGOTSKY; LURIA, 1996, p. 53). Por um certo período essas atividades ainda necessitam de apoiar-se em situações externas, mas com o passar do tempo acabam sendo internalizadas, tornando-se a base da comunicação interior, constituindo palavras próprias (BAKHTIN/VOLOCHINOV, (2006 [1929]).

A mediação colaborativa pressupõe justamente situações externas ao contexto pesquisado que, inicialmente, carecem do apoio do outro, de materiais concretos, de experimentos palpáveis que se configuram em situações de troca de experiências. Com o decorrer do tempo, essas inferências são internalizadas (pelo professor, pelo aluno) e passam a fazer parte das práticas intrínsecas e comuns a esses indivíduos.

Pesquisas de Vygotsky e Luria (1996) constatam que o uso de instrumentos a fim de suprir uma necessidade vital, um talher para se alimentar, por exemplo, é associado facilmente como imitação do outro e repetido naturalmente. Entretanto, a manipulação de "objetos externos para conseguir o controle do processo interno de memória" (VYGOTSKY; LURIA, 1996, p. 188) depende da maturidade psicológica da criança em processos culturais que surgem para facilitar as funções mentais, no desenvolvimento das Funções Psicológicas Superiores (FPS).

O desenvolvimento das FPS, internalizadas a partir de experiências externas, é evidenciada por Angelo (2015) na importância dos espaços de relações interpessoais no contexto da formação docente continuada:

[...] para que o professor aprenda a organizar os próprios processos mentais, construir conhecimentos e formas de ação na realidade da sala de aula, na dinâmica interativa com os outros sujeitos, que podem ser os colegas, o formador, o pesquisador, os alunos, a equipe pedagógica, os quais apontam, restringem, 
Contribuições da formação colaborativa para o ensino da leitura...

ampliam, conferem significados intrínsecos às ações educativas (ANGELO, 2015, p. 39).

Assim, o professor, a partir do trabalho colaborativo, não absorve integralmente aquilo que lhe foi apresentado como uma operação externa, mas reconstrói, reorganiza a partir das informações que já possuía como elementares, desenvolvendo novos conceitos.

O aprendizado amplia a zona de desenvolvimento real (ZDR), desperta processos internos de desenvolvimento capazes de operar na interação com o outro e, uma vez internalizados, esses processos tornam-se parte do desenvolvimento independente, oportunizando novos campos de desenvolvimento. $\mathrm{O}$ aprendizado, pois, dá-se de modo contínuo, reiterado. No que diz respeito à formação docente, ela não corresponde

[...] a uma assimilação individual, imediata, direta e passiva de teorias e modelos didáticos apresentados em eventos isolados de capacitação, mas decorre de uma interiorização progressiva, duradoura, sedimentada, de operações inicialmente constituídas na interação com os pares (ANGELO, 2015, p. 39).

Compreende-se que a pesquisa colaborativa pode propiciar o desenvolvimento do professor na formação continuada, de modo que ele passe a atuar na zona de desenvolvimento proximal (ZDP) dos alunos e consolide-a. Esta modalidade de pesquisa assume a colaboração como elemento fundamental ao processo de intervenção para desvendar sentidos da realidade. Nos termos de Magalhães (2004), no âmbito da pesquisa colaborativa, colaborar constitui uma ação com a finalidade de "possibilitar que os agentes participantes tornem seus processos mentais claros, expliquem, demonstrem, com o objetivo de criar, para os outros participantes, possibilidades de questionar, expandir, recolocar o que foi posto em negociação" (MAGALHÃES, 2004, p. 76). Esse processo de colaboração - interpsicológica - envolve o uso de instrumentos psicológicos - a mediação semiótica - que sustentam as relações entre professor/pesquisador e professor/colaborador e entre os próprios professores/colaboradores, constituindo a consciência dos sujeitos.

Aplica-se o conceito de ZDP tanto ao aluno quanto aos professores envolvidos na pesquisa colaborativa, uma vez que o professor interage com 
o pesquisador, com os outros professores e com os alunos, "[...] reelabora os conceitos aprendidos, responde e aprende a aplicá-los em outras situações de interação do cotidiano ou da sala de aula" (ANGELO, 2015, p. 40). E os conhecimentos transformados e consolidados alicerçam o trabalho com os alunos, que por sua vez se apropriam do conceito ensinado. Assim, o pesquisador atua junto ao professor/colaborador, de modo a dar forma ao trabalho do professor, dar sentido às relações entre o professor e os alunos, a ensiná-lo a escolher os instrumentos certos para trabalho pedagógico bem como a ensiná-lo a realizar adequadamente o encontro desses instrumentos com o aluno, processos que propiciam o desenvolvimento e a transformação do professor.

No desenvolvimento da pesquisa colaborativa, a apropriação se dá a partir da utilização da mediação instrumental, que passará a subsidiar o desenvolvimento do professor em formação, transformando-o em suas práticas. Segundo Angelo (2015, p. 46), os instrumentos "ao serem internalizados e apropriados e postos novamente nas relações interpessoais, geram a transformação do próprio sujeito e dos objetos culturais", ressignificando de modo individual, intrínseco, aquilo que acontece no social.

\section{Aspectos metodológicos da pesquisa}

Esta pesquisa constitui-se na interface entre a Linguística Aplicada contemporânea e a área da Educação, propondo-se à elaboração de conhecimentos para o agir do professor frente à diversidade que se encontra no interior das escolas, numa perspectiva transformadora. Emprega-se como procedimento de investigação a pesquisa colaborativa (MAGALHÃES, 2004; 2007). No caso desta pesquisa, toma-se o contexto da sala de aula para demonstrar como o trabalho colaborativo junto ao professor pode contribuir para o atendimento ao aluno com TFE.

A pesquisa foi realizada em uma escola municipal de ensino fundamental, localizada no interior do estado do Paraná. Participaram do estudo, além de uma das pesquisadoras - que desenvolveu as experiências colaborativas - a professora do $4^{\circ}$ ano, aqui denominada PSR. Outro participante da pesquisa é um aluno, denominado Davi, nove anos de idade, que frequentava a sala de aula comum, no período matutino, e a SRM em turno contrário, duas vezes por semana, com a mesma professora. 
Ressaltamos que esse aluno repetia pela segunda vez o $4^{\circ}$ ano. Davi apresenta TFE, conforme laudos registrados pela escola.

Três etapas constituíram a pesquisa: a) em um primeiro momento, foi realizada uma entrevista com a professora PSR e observações de aulas com propósitos de compreendermos as concepções da docente, no que se refere à educação inclusiva bem como conhecermos suas estratégias metodológicas aplicadas na leitura e na escrita do aluno Davi. Também, foram coletados materiais como laudos especializados da escola, referentes a Davi, e atividades de leitura e de escrita desenvolvidas por esse aluno nos dois contextos observados. A análise dos dados obtidos, dessa etapa, forneceu subsídios para o desenvolvimento das ações colaborativas; b) encontros da pesquisadora com PSR, a fim de realizarem leituras e refletirem sobre o atendimento de alunos com TFE. Para esta etapa foram selecionados e trabalhados os seguintes textos: "A educação especial na perspectiva da inclusão escolar" (BRASIL, 2010) 1; "O leitor e o processo da leitura" (MENEGASSI, 2010a); "O processo de produção textual" (MENEGASSI, 2010b); "Perguntas de leitura" (MENEGASSI, 2010c);c) entrevista com a professora PSR e novas observações de aulas, com o intuito de caracterizar as apropriações apresentadas por PSR e por Davi, a partir das mediações colaborativas.

Neste artigo, focalizam-se as estratégias metodológicas de leitura em classe comum, anteriormente e posteriormente às ações colaborativas. Para tanto, apresentam-se e discutem-se algumas atividades e cenas de interação, de forma a evidenciar as contribuições do trabalho colaborativo, no desenvolvimento da leitura e escrita de alunos com TFE.

\footnotetext{
${ }^{1}$ Justifica-se a escolha do texto em razão de a professora PSR despender atendimento especializado em SRM, mas não demonstrar conhecimento a respeito do papel que deve desempenhar em relação aos alunos que frequentam o programa e, também, em relação aos demais professores que atendem seus alunos no ensino regular.
} 


\section{Apresentação e discussão dos dados}

\subsection{Práticas de leitura antes das ações colaborativas}

Nas primeiras aulas observadas por uma das pesquisadoras, a professora trouxe para a classe uma fábula, intitulada "A raposa e a cegonha", de La Fontaine, que foi distribuída em cópias impressas para os alunos. Não houve qualquer motivação para a leitura, nem o acionamento de conhecimentos elaborados anteriormente sobre o conteúdo ou sobre o gênero textual. Os alunos receberam apenas o comando para que realizassem uma leitura silenciosa e, na sequência, respondessem as questões. Desse modo, a única finalidade estabelecida para a leitura foi a de ler para responder a perguntas de leitura.

\section{A RAPOSA E A CEGONHA}

\section{Fábula de La Fontaine}

Um dia a Raposa convidou a Cegonha para jantar e serviu-lhe sopa, que ambas gostavam muito, num prato raso.

- Estás a gostar da minha sopa? - perguntou, enquanto a Cegonha bicava em vão no líquido, sem conseguir comer nada.

- Como posso saber, se nem consigo comer? - respondeu a Cegonha, vendo a Raposa lamber a sopa com um ar todo deliciado.

Dias depois foi a vez de a Cegonha retribuir o gesto, pelo que convidou a Raposa para comer com ela na sua casa à beira do lago. Serviu-lhe a sopa num jarro largo embaixo e estreito em cima.

- Hummmm, está deliciosa, querida amiga! - exclamou a Cegonha, enfiando o comprido bico pelo gargalo. - Não achas?

Claro que a Raposa não achava nem podia achar nada, pois o focinho não passava pelo gargalo estreito do jarro. Tentou várias vezes sem sucesso até que, bastante mal humorada, se despediu da Cegonha, resmungando entredentes:

- Não te achei graça nenhuma...!

Figura1.Fábula para leitura

Fonte: Diário do professor 
Contribuições da formação colaborativa para o ensino da leitura...

\section{EST UDO DO TEXTO}

1. Quais são os personagens da história? a 200 prea Cleconba

2. Para que a raposa convidou a cegonha?

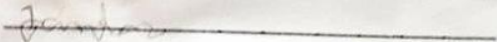

3. O que perguntou a raposa a Cegonha?

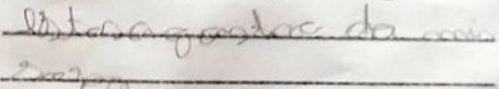

4. O que respondeu a cegon ha?

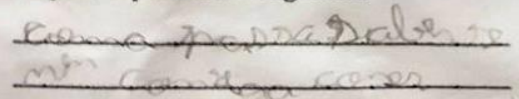

5. O que fez a Cegonha dias depois?

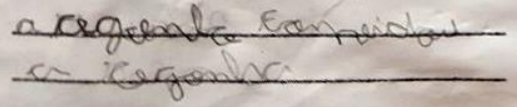

6. Onde ficava a casa da Cegonha? a lostina da lés

7. Onde a Cegonha serviu sopa a raposa?

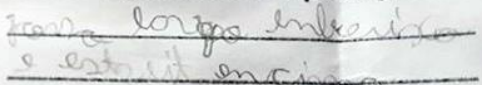

8. Como ficou a raposa após o jantar? mact archlignds mina

9. Analise as frases e marque aquela que explica a moral da história.
a) Casa de ferreiro, espeto de pau.
Aqui se faz, aqui se paga.
c) Quem burro nasce, burro morre.
d) A inveja não admite o mérito.

Figura 2. Estudo da fábula "A raposa e a cegonha" Fonte: caderno do aluno Davi

Quadro 1.Transcrição das questões da atividade e das respostas do aluno.

\begin{tabular}{|l|l|}
\hline Questão & Resposta \\
\hline 1. Quais são os personagens da história? & a raposa cegonha \\
2 Para que a raposa convidou a cegonha? & Jantar \\
3 O que perguntou a raposa a Cegonha? & $\begin{array}{l}\text { estasagostar da minha sopa } \\
\text { como passa saber se nen consiga } \\
\text { 4 O que respondeu a cegonha? }\end{array}$ \\
$\begin{array}{l}\text { coner } \\
\text { a cegonha convidou a cegonha }\end{array}$ \\
6 O que fez a Cegonha dias depois? & $\begin{array}{l}\text { a beira do lago } \\
\text { jarro largo enbaixo e estreito } \\
\text { 7 Onde a Cegonha serviu sopa a raposa? }\end{array}$ \\
$\begin{array}{l}\text { encima } \\
\text { nao te achei gracanenh-uma }\end{array}$ \\
\hline
\end{tabular}

Fonte: caderno do aluno Davi

Verifica-se que as questões 1 a 8requisitam a localização de informações explícitas, sendo que a maior parte delas pode ser respondida por meio de pareamento, estratégia em que o leitor toma as palavras que aparecem no comando, localiza-as no texto e copia o trecho seguinte, considerando-o como a resposta. Apenas a questão 9 exige uma reflexão acerca dos acontecimentos da narrativa, de modo a levar os alunos a 
selecionar e marcar a frase mais condizente com os ensinamentos da fábula. Não há, portanto, questões que conduzam os alunos à elaboração de inferências textuais e extratextuais e ao posicionamento crítico frente ao texto.

Ao considerar que Davi ainda apresenta muitas dificuldades para compreender um texto sem auxílio, as perguntas de localização de informações se configuram como uma importante atividade no início da formação do leitor. Entretanto, conforme evidencia Menegassi (2010a; 2010c), as perguntas de leitura que se oferecem aos alunos- tanto para aqueles que apresentam dificuldades, como Davi, como para aqueles que estão em níveis mais avançados - precisam guiá-los, gradativamente, ao processo de leitura, a fim de desenvolver um leitor proficiente, que não apenas copia informações, mas que compreende, levanta inferências e interpreta.

As respostas dadas por Davi são mero pareamento de informações e cópia de trechos do texto, sem evidenciar se de fato ele compreendeu a fábula. Assim, para responder a questão 8, por exemplo - "Como ficou a raposa após o jantar?" - Davi selecionou o fragmento final do texto e o copiou como resposta "nao te achei gracanenh-uma", evitando elaborar a resposta com palavras próprias com base em outras informações textuais, como "bastante mal humorada [...] resmungando entredentes". Também, observa-se que as respostas não constituem orações completas, mas palavras soltas, copiadas do texto, como em "jantar" (resposta da questão 2), ora sem o uso de elementos coesivos, como da conjunção aditiva em "a raposa cegonha" (resposta da questão 1), ora com repetição de palavras, que tornaram a resposta incoerente, como em "a cegonha convidou a cegonha" (resposta da questão 5). Ressalte-se que após os alunos terem efetuado o exercício, não houve qualquer discussão coletiva a respeito das perguntas e respostas.

Como continuação da atividade, a professora passou na lousa mais algumas questões que também direcionaram os alunos à localização e cópia do texto, objetivando a memorização de sinais de pontuação e localização de palavras com encontros consonantais, conteúdo trabalhado em aulas anteriores. Verifica-se, na atividade realizada por Davi (Figura 3) a desmotivação para a tarefa: copiou sem atenção, não obedeceu às linhas, repetiu-se em erros e borrões. A cópia das frases exclamativas e interrogativas solicitadas pelo exercício, apesar de localizadas e reproduzidas de acordo com o indicado, não apresentam maiúsculas 
Contribuições da formação colaborativa para o ensino da leitura...

iniciais, nem os sinais de pontuação esperados, evidenciando que ele ainda não reconhece a função desses sinais de pontuação, apesar de terem sido trabalhados exercícios que objetivavam contemplar esse aprendizado.

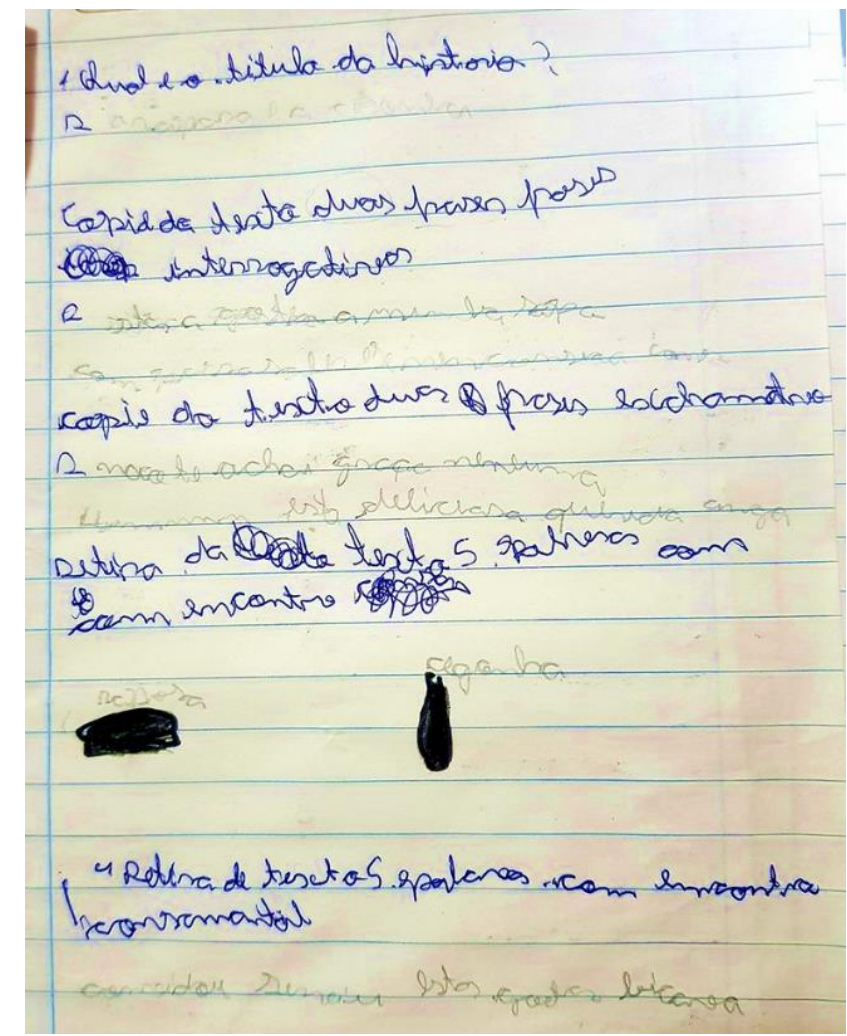

Figura 3.A raposa e a cegonha - exercícios de fixação Fonte: caderno do aluno Davi 
Quadro 2. Transcrição dos exercícios a partir do caderno do aluno.

\begin{tabular}{|l|} 
1. Qual é o título da história? R: araposa e a cegonha \\
Copie do texto duas frasesfrases \\
Interrogativas \\
sta a gostar a minha sopa \\
com possa saber senenconsigoconer \\
Copie do texto duas frases exclamativo \\
nao te achai graça nenhuma \\
hunnnnnesta deliciosa querida anga \\
4. Retira de texto 5 palavras com emcontro consonantal \\
Convidou serviu estas gostar bicava
\end{tabular}

\section{Fonte: caderno do aluno Davi}

Na realização da atividade, Davi recebeu auxílio da professora para localizar os sinais de pontuação no texto, visto que confunde as nomenclaturas 'exclamação' e 'interrogação'. Com o auxílio, ele localizou as frases solicitadas, mas as copiou de forma desatenciosa, sem registrar as maiúsculas iniciais ou os requeridos sinais de pontuação. A correção foi feita na lousa, para a qual Davi não fez nenhuma alteração, possivelmente porque não conseguiu entender onde havia errado.

Antes dessa correção coletiva, a professora retomou a fábula e pediu a um aluno que falasse sobre o que entendeu. Houve dificuldade na explanação, mesmo por parte dos alunos que apresentavam maior domínio das habilidades de leitura. Assim, eles mencionaram o ocorrido na fábula, mas não houve a compreensão de o porquê de as tentativas de tomar a sopa foram frustradas aos convidados em ambas ocasiões. Diante da dificuldade dos alunos de compreenderem a fábula e da dificuldade da professora em auxiliá-los na compreensão, a pesquisadora sugeriu à professora que pedisse que desenhassem as vasilhas nas quais foi servida a sopa. Embora tenha havido entusiasmo para o desenho, logo a professora percebeu a dificuldade dos alunos em retratar "um jarro largo embaixo e estreito em cima", conforme explicitado no texto, evidenciando a necessidade de se ensinar e mostrar também o desenho.

Após as explanações e o desenho das vasilhas, feito por um aluno também na lousa, a pesquisadora perguntou a eles o porquê da escolha do jarro e apenas uma aluna o relacionou ao bico longo da cegonha, fator que dá sentido à moral final. Novamente, fez-se necessário o esclarecimento 
das características da ave que, embora frequentemente citada, não é conhecida. A professora só então esclareceu também sobre características da raposa, inclusive sua fama de esperta, fingida, que sempre se dá bem. A partir dessas intervenções, a compreensão da fábula se deu de forma eficiente após um exercício cansativo de reprodução de informações que não foi capaz de propiciar a construção de sentidos textuais, nem mesmo pelos alunos com níveis de leitura mais avançados.

No que se refere ao atendimento ao aluno Davi, observou-se que, embora ele seja eventualmente auxiliado pela professora, não é convidado a participar das aulas; suas produções em geral não são revisadas com o intuito de concluí-las, sanar dúvidas, desenvolver a aprendizagem. Há uma preocupação excessiva com os registros no caderno do aluno, mesmo que, na maioria das vezes, eles sejam realizados por meio de cópias malfeitas, desmotivadas e desprovidas de compreensão.

\subsection{Ações colaborativas}

Ao tomar os pressupostos da teoria histórico-cultural concernentes à aprendizagem, uma vez que se entende o processo de formação continuada como um processo de aprendizagem, focalizaram-se as ações de formação nas funções que ainda não amadureceram no professor, mas que estão em processo de maturação, ou seja, assumiu-se como fio condutor das ações colaborativas o Nível de Desenvolvimento Potencial (NDP, VYGOTSKY, 1994) do professor, caracterizado como as capacidades em vias de serem elaboradas por meio da interação com outros sujeitos. Considera-se, por exemplo, que o professor tem como conhecimento aprendido e dominado - o Nível de Desenvolvimento Real (NDR), a necessidade de trabalhar com o aluno a localização de informações textuais, faltando-lhe consolidar conhecimentos, com auxílio de outros sujeitos - o NDP, acerca de outras etapas do processo de leitura, como a compreensão inferencial, necessária à formação e ao desenvolvimento do leitor.

Desse modo, nesta etapa da pesquisa, elegeram-se os conteúdos necessários no trabalho com o professor, bem como as estratégias pertinentes no desenvolvimento das ações colaborativas, de modo a movimentar as funções que estão em processo de maturação e que necessitam do auxílio do outro para se consolidar: a) conteúdos: etapas do processo de leitura: decodificação, compreensão, interpretação e retenção; produção e ordenação de perguntas de leitura; atividades de pré-leitura e 
finalidade de leitura; leitura compartilhada; especificidades da leitura em voz alta e leitura silenciosa; habilidades de leitura; b) estratégias: leitura de textos teórico-metodológicos para o ensino e a aprendizagem da leitura; discussão compartilhada dos textos lidos; discussão de situações de ensino em sala de aula; elaboração de planos de ensino; acompanhamento e intervenções nas práticas de leitura realizadas em sala de aula.

$\mathrm{O}$ conjunto desses conteúdos e estratégias buscou propiciar alterações na prática do professor em sala de aula junto ao aluno com TFE, por meio da compreensão dos aspectos intrínsecos ao processo de leitura, escrita e seu ensino. Dessa forma, essa etapa constitui-se a base sustentadora da pesquisa, visto que demonstra como a mediação colaborativa na formação continuada do professor reflete no processo de ensino e de aprendizagem, contribuindo para orientar as ações docentes, assessorando o professor a avaliar, redimensionar e planejar o ensino dos processos de leitura e escrita junto a alunos que apresentam diferentes níveis de leitura.

\subsection{Práticas de leitura após as ações colaborativas}

Este item apresenta e discute uma prática de leitura desenvolvida no $4^{\circ}$ ano do Ensino Fundamental, após o trabalho colaborativo efetuado por uma das pesquisadoras junto à professora. Para a primeira prática, foi escolhida a fábula "O rato do campo e o rato da cidade", de La Fontaine, em uma versão adaptada retirada da coletânea "Baú do professor" (GARCIA; GARCIA, 2007, p. 87-91).

A atividade foi iniciada com um exercício de pré-leitura, com o título escrito na lousa. A professora perguntou se já conheciam a história e as características do rato do campo e do rato da cidade, além do que eles imaginavam que pudesse ter acontecido: "Quais diferenças vocês acham que há entre os dois ratos? Como eles se vestem? Onde moram? De que se alimentam? Será que exercem algum trabalho? Como se divertem?". Na sequência, lembrou as partes que uma narrativa normalmente apresenta, atendo-se ao 'clímax', conceito ainda não conhecido pelos alunos. Desse modo, a professora ativou os conhecimentos espontâneos e propiciou aos alunos motivação e condições para uma participação mais interativa na leitura. Tratou-se, assim, de um trabalho com ênfase no desenvolvimento das habilidades de leitura, como: antecipar, a partir do título, algumas 
informações a respeito do texto a ser lido e reconheceras características e elementos da narrativa.

Em seguida, a professora dividiu a turma em grupos de quatro alunos, e distribuiu a cada aluno do grupo um excerto do texto, considerando os níveis de proficiência em leitura de cada aluno. Solicitou, então, que lessem e contassem aos colegas do grupo as ações ocorridas na fábula, com o intuito de organizar a sequência lógica da história. Entendese, com fundamentos em Vygotsky (1994), que o trabalho em grupo, quando bem orientado, subsidia o desenvolvimento de crianças com potencialidades diferentes e, em especial, da criança que possui dificuldade ou TFE. Nos termos de Vygotsky (1994, p. 59), “[...] distinguem-se dois grupos de funções: aquelas que as crianças já dominam, e aquelas que elas só podem pôr em ação sob orientação, em grupos, e em colaboração umas com as outras, ou seja, que elas não dominaram de forma independente". Dessa forma, na atividade, os alunos que apresentaram dificuldades na compreensão do texto, como o aluno Davi, foram auxiliados pelos colegas, de forma a confirmarem ou refutarem as suposições feitas na pré-leitura, outra habilidade de leitura trabalhada.

Davi recebeu o excerto mais curto do texto. Leu com dificuldade, necessitando do auxílio da professora e dos colegas para compreender o conteúdo. No entanto, interagiu com seu grupo, ouviu o enredo das partes lidas pelos colegas e colaborou na organização sequencial. Afirma-se, então, que a estratégia escolhida pela professora - leitura compartilhada em grupo - mostrou-se eficaz na promoção da participação do aluno Davi na atividade, como também na promoção do respeito pelo ritmo, pelas potencialidades e pelas dificuldades do outro, elementos imprescindíveis à convivência cidadã em sociedade.

Ao retomar a atividade no grande grupo, a professora fez questionamentos sobre a fábula, destacando as características do gênero, a autoria do texto, as relações da fábula com outros textos e aspectos do conteúdo:

\section{Cena 1}

PSR: E então, quem pode me dizer como era o rato do campo?

Aluno 1: Ele não era chique. Comia só milho e sementinha. Mas não tinha gato...

PSR: E o rato da cidade? 
Aluno 2: Era elegante. Usava gravata e morava numa casa bem bonita. Tinha muitos quadro e comida gostosa.

PSR: E o rato do campo gostou da vida que o rato da cidade levava?

Aluno 3: Nãããão! Ele queria a casa dele, bem tranquila...

PSR: E o que tinha de tão bom no campo?

Aluno 4: O ratinho podia comer o que gostava. E não tinha perigo...

A discussão compartilhada a respeito do texto é imprescindível para o desenvolvimento da competência leitora. Por meio dessa prática, o aluno pode: a) elaborar inferências, como a realizada pelo aluno 3 -"E o rato do campo gostou da vida que o rato da cidade levava?; Nãããão! Ele queria a casa dele, bem tranquila...", ou b) observar como as inferências são construídas pelo outro, como ocorreu com Davi, que não expôs sua opinião no grande grupo, mas se atentou às construções realizadas pelos colegas, processo que também constitui a aprendizagem escolar.

Torna-se essencial observar que diante de um aluno com dificuldades, como no caso de Davi, o professor precisa buscar metodologias que integrem os alunos a fim de desenvolvê-los, apesar das mais significativas diferenças que possam apresentar, em iguais condições. A depender das estratégias utilizadas pelo professor, o aluno pode se perceber como parte de um todo que interage e se auxilia, objetivando que o respeito pelas diferenças seja efetivo e a almejada participação nas práticas de linguagem ocorra no cotidiano escolar.

Posteriormente, os textos foram organizados e afixados no mural da classe, com intuito de se valorizar o trabalho efetivado em grupo e de garantir a circulação social dos textos.

$\mathrm{Na}$ sequência, a professora solicitou aos alunos que escrevessem uma carta para o rato da cidade para convencê-lo a vir morar no campo, aprofundando o conhecimento adquirido na leitura da fábula, transformando os sentidos textuais e refletindo sobre as condições de produção textual: destinatário (o rato da cidade), finalidade (convencer o rato da cidade a morar no campo), gênero (carta pessoal) e posição do autor (rato do campo). Davi escreveu um texto em que misturou uma narração e aspectos do gênero carta, o que levou PSR a realizar intervenções junto a ele, por exemplo as registradas na Cena 2: 


\section{Cena 2}

PSR: Olha, Davi, você começou a carta certinho, porque é como se estivesse conversando com o rato. Convidou ele pra vir experimentar os queijos. Mas depois você só conta coisas que aconteceram na história que lemos. O que é que vocês tinham que fazer na carta?

Davi: Chamar o rato pra vim na nossa casa...

PSR: Isso. E o que é preciso fazer para convencer ele?

Davi: Não sei...

PSR: O que você diria para um amigo se quisesse convencê-lo a ir passear na tua casa?

Davi: Ah... mas eu só vou contar pra ele que tem queijo que ele gosta.

PSR: Tá certo... Vamos organizar a sua cartinha?

Constatou-se que, nas orientações ao aluno Davi, PSR amplia seu olhar para o texto do aluno, rompendo com a noção de que a intervenção didática é sinônimo de correção de erros de ortografia, concordância e pontuação, dando mostras da internalização das teorias estudadas e trabalhadas com ele. Assim, PSR auxilia Davi a expandir a leitura da fábula, trazendo elementos novos, frutos da criação individual: “[...] depois você só conta coisas que aconteceram na história que lemos"; "E o que é preciso fazer para convencer ele?"; "O que você diria para um amigo se quisesse convencê-lo a ir passear na tua casa?".

\section{Considerações finais}

Conforme evidenciou-se no levantamento inicial da pesquisa, as práticas de leitura no $4^{\circ}$ ano do ensino fundamental ocorriam sem nenhuma contextualização e nenhum auxílio para o trabalho desenvolvido após a leitura. $\mathrm{O}$ texto era distribuído em meio impresso, lido de forma silenciosa e trabalhado a partir de perguntas que levavam ao pareamento de informações, sem promover a compreensão. Os processos de leitura e a mediação do professor eram desconsiderados.

Após as ações colaborativas, pautadas em leituras e discussões acerca do processo de leitura, em reflexões sobre as situações de leitura em sala de aula, em elaboração e aplicação de planejamentos e de atividades orientadas, constatou-se atividades que incentivam a participação de todos 
os alunos, valorizando habilidades e respeitando diferenças, e práticas de leitura e de escrita que mobilizam os conhecimentos dos alunos e impulsionam à descoberta e à ampliação de capacidades individuais.

Assim, afirma-se que houve um redimensionamento do trabalho pedagógico que trouxe contribuições para o desenvolvimento da leitura de todos os alunos, não apenas do aluno Davi. O Quadro3 sintetiza as atividades e as habilidades de leitura trabalhadas em sala de aula, após as ações colaborativas:

Quadro 3. Atividades e habilidades de leitura após as ações colaborativas

\begin{tabular}{|c|c|c|}
\hline Fase & Atividades & Habilidades \\
\hline $\begin{array}{l}\text { Antes } \\
\text { da leitura }\end{array}$ & $\begin{array}{l}\text { Escrita do título no quadro } \\
\text { Questionamentos orais }\end{array}$ & $\begin{array}{l}\text { - Realizar antecipações a respeito } \\
\text { do texto. } \\
\text { - Identificar as características da } \\
\text { narrativa. } \\
\text { - Confirmar as informações } \\
\text { registradas na pré-leitura. }\end{array}$ \\
\hline $\begin{array}{l}\text { Durante } \\
\text { a leitura }\end{array}$ & \begin{tabular}{l}
\multicolumn{2}{l}{ Leitura silenciosa } \\
Leitura compartilhada \\
Organização, de modo \\
compartilhado com $r$ \\
colegas, da sequência da \\
narrativa
\end{tabular} & $\begin{array}{l}\text { - Recontar o que leu, fazendo } \\
\text { paráfrases. } \\
\text { - Estabelecer relações entre partes } \\
\text { do texto. } \\
\text { - Organizar a sequência lógica da } \\
\text { narrativa }\end{array}$ \\
\hline \multirow[t]{4}{*}{$\begin{array}{l}\text { Após } \\
\text { a leitura }\end{array}$} & $\begin{array}{l}\text { Discussão oral a respeito dos } \\
\text { textos lidos }\end{array}$ & $\begin{array}{l}\text { - Inferir significado de palavras e } \\
\text { expressões a partir do contexto. } \\
\text { - Inferir informações a respeito do } \\
\text { texto lido. } \\
\text { - Estabelecer relações de } \\
\text { intertextualidade. } \\
\text { - Identificar a autoria do texto. } \\
\text { - Identificar características do } \\
\text { gênero textual trabalhado. }\end{array}$ \\
\hline & $\begin{array}{l}\text { Organização dos textos em } \\
\text { mural da classe. }\end{array}$ & $\begin{array}{l}\text { - Promover a circulação social dos } \\
\text { textos. }\end{array}$ \\
\hline & $\begin{array}{l}\text { Transformação do gênero } \\
\text { lido (transformar uma fábula } \\
\text { em uma carta) }\end{array}$ & $\begin{array}{l}\text { - Transformar um gênero em outro } \\
\text { gênero. } \\
\text { - Refletir acerca das condições de } \\
\text { produção de texto. }\end{array}$ \\
\hline & Reprodução do texto lido & - Recontar, por escrito, o texto lido. \\
\hline
\end{tabular}

Fonte: As autoras 
Verifica-se que as práticas pedagógicas junto ao aluno Davi, fundamentadas nos processos e nas habilidades de leitura, principalmente durante os atendimentos individualizados, propiciou a ele ler com significação, numa posição responsiva. $O$ aluno, ao conhecer suas potencialidades, percebeu-se mais capaz e adquiriu uma relação mais positiva com a leitura. Davi mostra-se capaz de realizar leitura silenciosa identificando informações explícitas, participa de atividades de pré-leitura colaborando oralmente quando solicitado, estabelece inferências e interpreta textos com auxílio do professor ou colegas, manifestando um ponto de vista acerca do que foi lido e compreendido; desse modo, observase o desenvolvimento de capacidades para níveis mais elevados de leitura que o conduzem paulatinamente a um leitor cada vez mais interativo.

Assim, o trabalho colaborativo junto ao professor contribuiu para o atendimento ao aluno com TFE. Por meio das relações interpessoais, o professor elaborou conhecimentos e formas de ação na realidade da sala de aula, de modo a desafiar o aluno para além de seu nível de desenvolvimento real com a proposição de situações desencadeadoras do nível de desenvolvimento potencial (VYGOTSKY, 1994).

\section{Referências}

AMERICAN PSYCHIATRIC ASSOCIATION [APA]. Manual diagnóstico e estatístico de transtornos mentais [recurso eletrônico]: DSM5 [tradução: Maria Inês Corrêa Nascimento, et al.]; revisão técnica: Aristides Volpato Cordioli ... [et al.] 5. ed. Porto Alegre: Artmed, 2014.

ANGELO, C. M. P. Mediações colaborativas e pedagógicas em sala de apoio à aprendizagem de língua portuguesa. $390 \mathrm{f}$. Tese (Doutorado em Letras) - Universidade Estadual de Maringá, Maringá, 2015. Disponível em: 〈http://www.ple.uem.br〉. Acesso em 10 mar. 2019.

BAKHTIN, M./VOLOCHINOV, V. N. Marxismo e filosofia da linguagem. São Paulo: Hucitec, 2006 [1929].

BRASIL. Ministério da Educação. Secretaria de Educação Especial. A educação especial na perspectiva da inclusão escolar: o atendimento 
educacional especializado para alunos com deficiência intelectual. v. 2. Brasília, 2010.

GARCIA, W.; GARCIA, O. Baú do professor para 9 e 10 anos: histórias e oficinas pedagógicas. v. 1. 1. ed. Belo Horizonte, MG: Editora FAPI, 2007.

MAGAlHÃES, M. C. C. (Org.). A formação do professor como um profissional crítico: linguagem e reflexão. Campinas, SP: Mercado de Letras, 2004.

A pesquisa colaborativa em linguística aplicada. In: FIDALGO, S. S; SHIMOURA, A. S. (Orgs.). Pesquisa crítica de colaboração: um percurso na formação docente. São Paulo: Ductor, 2007. p. 148-157.

MENEGASSI, R. J. O leitor e o processo de leitura. In: GRECO, E. A.; GUIMARÃES, T. B. (Orgs.) Leitura: aspectos teóricos e práticos. Maringá: Eduem, 2010a.p. 35-59.

O processo de produção textual. In: SANTOS, A. R. dos; GRECO, E. A.; GUIMARÃES, T. B. (Orgs.). A produção textual e o ensino. Maringá: Eduem, 2010b. p. 75-101.

. Perguntas de leitura. In: MENEGASSI, R. J. (Org.). Leitura $e$ ensino. 2.ed. Maringá: Eduem, 2010c. p. 167-189.

PARANÁ. Secretaria do Estado da Educação. Curso de avaliação psicoeducacional no contexto escolar: subsídios para avaliação psicoeducacional no contexto escolar: orientações pedagógicas. Curitiba, 2013.

Disponível

em: <http://www.educadores.diaadia.pr.gov.br/arquivos/File/ed_especial/subsid ios_avaliacao_contexto_escolar.pdf $>$. Acesso em: 21 set. 2018.

PARANÁ. Secretaria do Estado da Educação. Instrução No 09/2018: SUED/SEED. Estabelece critérios para o Atendimento Educacional Especializado por meio da Sala de Recursos Multifuncionais. Curitiba: 2018. Disponível em: http://www.educacao.pr.gov.br/arquivos/File/instrucoes/2018/instrucao 09 2018.pdf. Acesso em: 21 set. 2018.

VYGOTSKY, L. S. A formação social da mente: o desenvolvimento dos processos psicológicos superiores. In: COLE, Michael [et al.] (Orgs.). 
Contribuições da formação colaborativa para o ensino da leitura...

Tradução de José Cipolla Neto, Luis Silveira Menna Barreto, Solange Castro Afeche. 5. ed. São Paulo: Martins Fontes, 1994.

. Pensamento e linguagem. Tradução Jefferson Luiz Camargo. São Paulo: Martins Fontes, 1998.

.; LURIA A. R. Estudos sobre a história do comportamento: símios, homem primitivo e criança. Tradução de Lólio Lourenço de Oliveira. Porto Alegre: Artes Médicas, 1996.

Recebido em: 25/08/2019

Aceito em: 26/12/2019

Title: Contributions of collaborative education to the teaching of reading to students with specific functional disorders 